\title{
Cardiohepatic interactions - cirrhotic cardiomyopathy and cardiac cirrhosis
}

\author{
Agnieszka Witczak'1, Andrzej Prystupa', Shaliny Ollegasagrem', Grzegorz Dzida' \\ ${ }^{1}$ Department of Internal Medicine, Medical University of Lublin, Poland
}

Witczak A, Prystupa A, Ollegasagrem S, Dzida G. Cardiohepatic interactions - cirrhotic cardiomyopathy and cardiac cirrhosis. J Pre-Clin Clin Res. 2015; 9(1): 79-81. doi: 10.5604/18982395.1157582

\begin{abstract}
Interactions between the heart and the liver have been under investigation for many years. Cirrhotic cardiomyopathy characterized by hyperdynamic and hyporeactive circulation has been described in patients with advanced liver disease. Liver disease due to heart failure comprises acute hypoxic hepatitis due to reduced hepatic blood flow and congestive hepatopathy due to increased pressure within hepatic veins. Despite some specific characteristics, clinical presentation and treatment of cirrhotic heart disease and cardiac liver diseases are similar to the management of heart failure and liver cirrhosis of other origin.
\end{abstract}

\section{Key words}

cirrhotic cardiomyopathy, hypoxic hepatitis, congestive hepatopathy

\section{INTRODUCTION}

There are many reports published on the interactions between the heart and the liver, including cirrhotic cardiomyopathy, acute liver injury and chronic congestive hepatopathy. Cardiac dysfunction observed in patients with cirrhosis is characterized by increased cardiac output due to hyperdynamic circulation. Acute ischaemic hepatitis results mostly from decreased blood supply to the peripheral organs, and congestive hepatopathy reflects impaired blood return to the right ventricle with increased filling pressure [1]. This study present a short report on hepato-cardiac relations.

Definition of cirrhothic cardiomyopathy. Heart dysfunction has been observed in the course of liver cirrhosis of different origin [2]. It is mostly characterized by increased heart rate, increased cardiac output and reduced peripheral vascular resistance, called hyperdynamic circulation [3]. Vascular reactivity to vasopressors, such as adrenaline and angiotenisin II, is decreased in liver cirrhosis so the circulation and is also called hyporeactive [4]. To diagnose the so-called cirrhotic cardiomyopathy chronic cardiac dysfunction characterized by systolic dysfunction, presenting with impaired contraction in response to stress and/or impaired left ventricular relaxation with electrophysiological abnormalities in the absence of known cardiac disease, need to be revealed [5]. At the 2005 World Congress of Gastroenterology in Montreal, Canada, diagnostic criteria for cirrhotic cardiomyopathy were presented, including impaired response to exercise, resting ejection fraction $<55 \%$, impaired relaxation with the ratio of early to late phases of ventricular filling E/A ratio $<1.0$, prolonged deceleration time $(>200 \mathrm{~ms})$, or prolonged isovolumetric relaxation time $(>80 \mathrm{~ms})$. Minor criteria included electrophysiological abnormalities, chronotropic incompetence, electromechanical uncoupling/dyssynchrony, prolonged QTc interval, enlargement of left atrium, increased myocardial mass, increased brain natriuretic peptide level (BNP) and pro-BNP, or increased troponin I level [6].

Address for correspondence: Andrzej Prystupa, Department of Internal Medicine, Medical University of Lublin, Staszica 16, Lublin, Poland

E-mail: aprystup@mp.pl

Received: 13 November 2014; accepted: 08 December 2014
Pathogenesis of cirrhotic cardiomyopathy - haemodynamic changes. Different mechanism have been reported to be responsible for the development of systolic dysfunction in cirrhotic cardiomyopathy, including down-regulation of betaadrenergic receptors as the result of increased sympathetic drive, activation of renin-angiotensin-aldosterone system, abnormalities of membrane calcium channels, and the deleterious effect of some humoral factors, e.g. nitric oxide and cytokines, as well as apoptosis mediated by cytokines, and TGF-beta, mostly $[7,8]$. Subsequent, lower than normal increase in the amount of ejected blood after exercise has been observed mostly as the result of decreased cardiovascular reactivity $[9,10]$. Diastolic dysfunction is characterized by impaired relaxation resulting in an increase in left ventricular end-diastolic pressure [11]. Parameters of diastolic dysfunction used in the evaluation of patients with liver cirrhosis follow general recommendations [12]. On echocardiography, increased left ventricular end-diastolic volume and left atrial volumes are observed in patients with liver cirrhosis [13]. Studies comprising patients after transjugular intrahepatic portosystemic shunts showed increased pulmonary capillary wedge pressure, as well as increased pulmonary resistance, suggesting significant diastolic dysfunction [14]. Sodium and water retention was also reported to induce left ventricular hypertrophy resulting in diastolic dysfunction [15]. This mechanism may be also responsible for diastolic dysfunction in cirrhotic cardiomyopathy due to hyperaldosteronism. Hypertrophy, fibrosis and subendothelial oedema result in increased stiffness of the myocardial wall, with high filling pressures. Another risk factor for the development of diastolic dysfunction is impaired bowel function, including decreased motility and damage of mucosa with increased permeability. Subsequent bacterial translocation increases exposure to bacterial toxin as well as TNF- $\alpha$ which have been shown to have negative inotropic effect on the heart [16]. Some haemodynamic effects of liver disease are shown in Table 1.

Pathogenesis of cirrhotic cardiomyopathy - electrophysiological abnormalities. Autonomic dysfunction characterized by increased sympathetic drive and decreased vagal tone, as well as decreased density of potassium and calcium currents in ventricular myocytes, seem to be responsible 
Table 1. Haemodynamic pattern in liver disease

\begin{tabular}{lc}
\hline $\begin{array}{c}\text { Systemic } \\
\text { circulation }\end{array}$ & $\begin{array}{r}\text { arterial blood pressure } \downarrow \text {, vascular resistance } \downarrow \text {, blood volume } \uparrow, \\
\text { cerebral blood flow } \downarrow \text {, renal blood flow } \downarrow\end{array}$ \\
\hline Heart & $\begin{array}{l}\text { heart rate } \uparrow, \text { cardiac output } \uparrow, \text { left atrial volume, } \\
\text { left ventricular volume } \rightarrow \text { pulmonary artery pressure } \uparrow\end{array}$ \\
\hline $\begin{array}{l}\text { Pulmonary } \\
\text { circulation }\end{array}$ & blood flow $\uparrow$, vascular resistance $\downarrow$, blood volume $\downarrow$ \\
\hline
\end{tabular}

for electrophysiological disorders, including prolongation of QT interval and impaired electromechanical coupling. Fortunately, life-threatening arrhythmias are uncommon in cirrhotic cardiomyopathy [17]. QT prolongation was reported to be the marker of fatal prognosis, but recent studies have not supported this finding. After liver transplant, QT was observed to decrease to normal values [18]. Electrophysiological abnormalities also include electromechanical dyssynchrony, resulting in contractile dysfunction and reduction of left ventricular ejection fraction [19].

Acute cardiogenic liver injury. Since the liver is quite sensitive to ischemia, any heart dysfunction may result in liver disorder. Hypoxic liver disease, also called hypoxic hepatitis, is typical for acute heart failure, and congestive hepatopathy is usually observed in advanced chronic heart failure with right ventricular involvement. Acute cardiogenic liver injury (ACLI) described in patients with cardiogenic shock although not specific for heart dysfunction as the underlying disease, has been most commonly observed in patients with heart failure [20]. Fatty liver disease resulting from lipid disorders, obesity or diabetes mellitus, increases the risk of ischaemic injury [21]. Zone 3 hepatocytes surrounding the central vein within the hepatic acinus seem to be mostly exposed to ischaemia, resulting in their necrosis, subsequent fibrotic reparative process and the development of cirrhosis [22]. Damage of zone 3 hepatocytes, together with dilatation of hepatic sinusoids and perivenular oedema promoting liver fibrosis, are also the result of increased venous pressure in the course of right heart failure, especially with significant tricuspid regurgitation. Hypoxic hepatitis seems to result not only from impaired liver perfusion but also from hepatic congestion due to heart failure [23]. Decreased venous return to the right ventricle results in vascular stasis, with subsequent clot formation within the hepatic veins, and venous congestion makes the liver even more susceptible to ischaemic injury [24]. Decreased arterial blood supply due to left ventricular dysfunction, together with impaired venous return to the failing right ventricle, results in liver enlargement as well as an increase in liver enzymes [25]. Although clinical presentation of cardiacrelated acute liver injury, including weakness, apathy, mental confusion, hepatic coma, jaundice, bleeding diathesis, does not differ significantly from those of other, specific origin, the laboratory pattern may suggest underlying heart disease [2]. Sudden and significant increase in alanine aminotransferase activity 10 - 20 times above the upper normal value, with obvious decrease within the following 72 hours, is typical for hypoxia different from viral or alcoholic liver disease. Lactate dehydrogenase level has been also observed to increase abruptly due to liver hypoxia, and ALT and LDH ratios lower than 1.5 reinforces the suspicion of hypoxic hepatitis [25].

Clinical and biochemical data are usually sufficient to establish the diagnosis of the liver injury related to heart disease, but sometimes a liver biopsy may be needed [26]. Bilirubin level has been also revealed to increase in the course of cardiac liver disease, being the strongest risk factor for poor prognosis. Low albumin, if present, has also been a marker of low survival rate. Together with albumin, the synthesis of coagulation factors is limited, leading to bleeding complication [27].

Cirrhotic hepatopathy. Congestive hepatopathy, resulting mostly from increased right ventricular filling pressure, may be difficult to distinguish from liver cirrhosis, and its clinical presentation suggests underlying cholelithiasis, peptic ulcer or colitis [28]. The most important mechanisms responsible for the development of congestive hepatopathy include hepatic congestion, decreased hepatic blood flow and hypoxemia [25]. Histological findings usually reveal atrophy and necrosis of hepatocytes surrounding the central vein, as well as bile thrombi resulting in cholestasis [26]. Abnormal liver function tests observed in the course of congestive hepatopathy do not show such a clear specific pattern as in patients with hypoxic hepatitis. They reflect heart failure induced cholestasis and heart failure induced liver cytolysis. Heart failure induced liver cytolysis is the result of hypoperfusion and subsequent hypoxygenation of liver cells [29]. Histological findings of liver cytolysis reveal alternating areas of centrilobular necrosis (zone 3 acini) and haemorrhage. Zone 3 is the furthest region of the liver lobule that receives blood from the portal vein and hepatic artery [30]. Transaminases and lactate dehydrogenase have been reported to be elevated. Advanced heart failure seems to result in cholestasis, based on an increased level of bilirubin, alkaline phosphatase and gamma-glutamyl transpeptidase. Together with the blood vessels that are constricted by the surrounding oedema, the bile canaliculi and ductules within the lobules are also compressed. The increased hydrostatic pressure in the liver sinusoids, as a compensatory mechanism then leads to hypertrophy of hepatocytes, which further compresses the bile canaliculis [28]. Cholestatic enzymes, together with low albumin and high bilirubin, have been shown to be markers for poor outcome in chronic heart failure [31]. Although irreversible liver cirrhosis is an absolute contraindication for sole heart transplantation, reports have been published reports on the regression of cardiac cirrhosis after heart transplantation [32]. Some characteristics of liver disorders related to heart disease are shown in Table 2.

Table 2. Liver disorders of cardiac origin

\begin{tabular}{ll}
$\begin{array}{l}\text { Acute ischaemic } \\
\text { hepatitis }\end{array}$ & \multicolumn{1}{c}{$\begin{array}{c}\text { tissue hypoxia, marked elevation of AST, ALT, LDSH, ALP } \\
\text { and bilirubin }\end{array}$} \\
\hline $\begin{array}{l}\text { Congestive } \\
\text { hepatopathy }\end{array}$ & $\begin{array}{l}\text { perisinusoidal oedema, sinusoidal thrombosis, ascites, } \\
\text { jaundice, normal or mild elevation of AST, ALT, LDSH, ALP and } \\
\text { bilirubin }\end{array}$ \\
\hline
\end{tabular}

\section{CONCLUSIONS}

Interactions between the heart and the liver have been well defined. Since the clinical effect of both cirrhotic cardiomyopathy and cardiac cirrhosis is similar to heart and liver disorders of other origin, management follows the current recommendations for heart failure and liver disease $[33,34,35]$. 


\section{REFERENCES}

1. Fouad YM, Yehia R. Hepato-cardiac disorders. World J Hepatol. 2014; 27; 6(1): 41-54

2. Chayanupatkul M, Liangpunsakul S. Cirrhotic cardiomyopathy: review of pathophysiology and treatment. Hepatol Int. 2014; 8(3): 308-315.

3. Kowalski H, Abelmann WH. The cardiac output at rest in Laennec's cirrhosis. J Clin Invest. 1953; 32: 1025-1033.

4. Moller S, Henriksen JH. Cirrhotic cardiomyopathy: a pathophysiological review of circulatory dysfunction in liver disease. Heart. 2002; 87: 9-15.

5. Krag A, Bendtsen F, Henriksen JH, Moller S. Low cardiac output predicts development of hepatorenal syndrome and survival in patients with cirrhosis and ascites. Gut. 2010; 59: 105-110.

6. Moller S, Henriksen JH. Cardiovascular complications of cirrhosis. Gut. 2008; 57: 268-278.

7. Lee SS, Marty J, Mantz J, Samain E, Braillon A, Lebrec D. Desensitization of myocardial beta-adrenergic receptors in cir-rhotic rats. Hepatology. 1990; 12: 481-485

8. Liu H, Ma Z, Lee SS. Contribution of nitric oxide to the patho-genesis of cirrhotic cardiomyopathy in bile duct-ligated rats. Gastroenterology. 2000; 118: 937-944.

9.Henriksen JH, Fuglsang S, Bendtsen F, Christensen E, Møller S. Arterial compliance in patients with cirrhosis. High stroke volume/ pulse pressure ratio as an index of elevated arterial compliance. Am J Physiol. 2001; 280: G584-G594.

10. Wong F, Girgrah N, Graba J, Allidina Y, Liu P, Blendis L. The cardiac response to exercise in cirrhosis. Gut. 2001;49:268-275.

11. Sampaio F, Pimenta J, Bettencourt N, Fontes-Carvalho R, Silva AP, Valente J, et al. Systolic and diastolic dysfunction in cirrhosis: a tissueDoppler and speckle tracking echocardiography study. Liver Int. 2013; 33: $1158-1165$.

12. Nagueh SF, Appleton CP, Gillebert TC, FESC, Marino PN, FESC, Oh JK, Smiseth OA, FESC, Waggoner AD, Flachskampf FA, FESC, Pellikka PA, Evangelista A Evaluation of left ventricular diastolic function by echocardiography: EAE/ASE Recommendations EJE 2009; 10(2): 165-193.

13. Nagueh SF, Appleton CP, Gillebert TC, Marino PN, Oh JK, Smiseth $\mathrm{OA}$, et al. Recommendations for the evaluation of left ventricular diastolic function by echocardiography. J Am Soc Echocardiogr. 2009; 22: 107-133.

14. Huonker M, Schumacher YO, Ochs A, Sorichter S, Keul J, Rossle M. Cardiac function and haemodynamics in alcoholic cirrhosis and effects of the transjugular intrahepatic portosystemic stent shunt. Gut. 1999; 44: 743-748.

15. Takeda Y, Yoneda T, Demura M, Miyamori I, Mabuchi H. Sodiuminduced cardiac aldosterone synthesis causes cardiac hypertrophy. Endocrinology. 2000; 141: 1901-1904

16. Karagiannakis DS, Vlachogiannakos J, Anastasiadis G, VafiadisZouboulis I, Ladas SD. Frequency and severity of cirrhotic cardiomyopathy and its possible relationship with bacterial endo-toxemia. Dig Dis Sci. 2013; 58: 3029-3036.

17. Trevisani F, Merli M, Savelli F, Valeriano V, Zambruni A, Riggio O, Caraceni P, Domenicali M, Bernardi M. QT interval in patients with non-cirrhotic portal hypertension and in cirrhotic patients treated with transjugular intrahepatic porto-systemic shunt. J Hepatol. 2003; 38(4): 461-467.

18. Bal JS, Thuluvath PJ. Prolongation of QTc interval: relationship with etiology and severity of liver disease, mortality and liver transplantation. Liver Int. 2003; 23(4): 243-248.

19. Henriksen JH, Fuglsang S, Bendtsen F, Møller S. Arterial hypertension in cirrhosis: arterial compliance, volume distribution, and central haemodynamics. Gut. 2006; 55(3): 380-387.
20.Henrion J. Hypoxic hepatitis. Liver Int. 2012; 32(7): 1039-1052.

21. Birrer R, Takuda Y, Takara. Hypoxic hepatopathy: pathophysiology and prognosis. Intern Med. 2007; 46: 1063-1070.

22. Kavoliuniene A, Vaitiekiene A, Cesnaite G.Congestive hepatopathy and hypoxic hepatitis in heart failure: a cardiologist's point of view. Int J Cardiol. 2013; 1; 166(3): 554-558.

23. Fuhrmann V, Kneidinger N, Herkner H, Heinz G, Nikfardjam M, Bojic A, Schellongowski P, Angermayr B, Kitzberger R, Warszawska J, Holzinger U, Schenk P, Madl C. Hypoxic hepatitis: underlying conditions and risk factors for mortality in critically ill patients. Intensive Care Med. 2009; 35(8): 1397-405.

24. Gelow JM, Gelow AS, Desai CP, Hochberg JN, Glickman MM, Givertz JC. FangClinical predictors of hepatic fibrosis in chronic advanced heart failure. Circ Heart Fail. 2010; 3(1): 59-64.

25. Myers RP, Cerini R, Sayegh R, Moreau R, Degott C, Lebrec D, Lee SS. Cardiac hepatopathy: clinical, hemodynamic, and histologic characteristics and correlations. Hepatology 2003; 37: 393-400.

26. Dai DF, Swanson PE, Krieger EV, Liou IW, Carithers RL, Yeh MM. Congestive hepatic fibrosis score: a novel histologic assessment of clinical severity. Mod Pathol. 2014; 27(12):1552-1558.

27. Allen LA1, Felker GM, Pocock S, McMurray JJ, Pfeffer MA, Swedberg K, Wang D, Yusuf S, Michelson EL, Granger CB; CHARM Investigators. Liver function abnormalities and outcome in patients with chronic heart failure: data from the Candesartan in Heart Failure: Assessment of Reduction in Mortality and Morbidity (CHARM) program. Eur J Heart Fail. 2009; 11(2): 170-177.

28. Lau GT, Tan HC, Kritharides L. Type of liver dysfunction in heart failure and its relation to the severity of tricuspid regurgitation. Am J Cardiol. 2002; 90(12): 1405-1409.

29. Møller S, Bernardi M. Interactions of the heart and the liver. Eur Heart J. 2013; 34(36): 2804-2811.

30. Li P, Robertson TA, Zhang Q, Fletcher LM, Crawford DH, Weiss M, Roberts MS. Hepatocellular necrosis, fibrosis and microsomal activity determine the hepatic pharmacokinetics of basic drugs in right-heartfailure-induced liver damage. Pharm Res. 2012; 29(6): 1658-1669.

31. Chokshi A1, Cheema FH, Schaefle KJ, Jiang J, Collado E, Shahzad K, Khawaja T, Farr M, Takayama H, Naka Y, Mancini DM, Schulze PC. Hepatic dysfunction and survival after orthotopic heart transplantation: application of the MELD scoring system for outcome prediction. J Heart Lung Transplant. 2012; 31(6): 591-600.

32. Crespo-Leiro MG1, Robles O, Paniagua MJ, Marzoa R, Naya C, Flores X, Suárez F, Gómez M, Grille Z, Cuenca JJ, Castro-Beiras A, Arnal F. Reversal of cardiac cirrhosis following orthotopic heart transplantation. Am J Transplant. 2008; 8(6): 1336-1339.

33. McMurray JJ, Adamopoulos S, Anker SD, et al. ESC guidelines for the diagnosis and treatment of acute and chronic heart failure 2012: the task force for the diagnosis and treatment of acute and chronic heart failure 2012 of the European Society of Cardiology. Developed in collaboration with the Heart Failure Association (HFA) of the ESC. Eur J Heart Fail. 2012; 14: 803-869.

34. Lee WM1, Stravitz RT, Larson AM. Introduction to the revised American Association for the Study of Liver Diseases Position Paper on acute liver failure 2011. Hepatology. 2012; 55(3): 965-967.

35. Chalasani N, Younossi Z, Lavine JE, Diehl AM, Brunt EM, Cusi K, Charlton M, Sanyal AJ; American Gastroenterological Association; American Association for the Study of Liver Diseases; American College of Gastroenterology. The diagnosis and management of non-alcoholic fatty liver disease: practice guideline by the American Gastroenterological Association, American Association for the Study of Liver Diseases, and American College of Gastroenterology. Gastroenterology. 2012; 142(7): 1592-1609. 